\title{
Electrochemical immunosensor for sensitive determination of transforming growth factor (TGF) - $\beta 1$ in urine
}

\author{
E. Sánchez-Tirado, G. Martínez-García, A. González-Cortés, P. Yáñez-Sedeño*, \\ J.M. Pingarrón \\ Department of Analytical Chemistry, Faculty of Chemistry, University Complutense of Madrid, 28040 Madrid, Spain
}

\section{A R T I C L E I N F O}

\section{Article history:}

Received 29 March 2016

Received in revised form

11 May 2016

Accepted 30 May 2016

\section{Keywords:}

Transforming growth factor- $\beta 1$ (TGF- $\beta 1$ )

Electrochemical immunosensor

Signal amplification

Urine

\begin{abstract}
A B S T R A C T
The first amperometric immunosensor for the quantification of TGF- $\beta 1$, a cytokine proposed as a biomarker for patients having or at risk for renal disease, is described in this work. The immunosensor design involves disposable devices using carboxylic acid-functionalized magnetic microparticles supported onto screen-printed carbon electrodes and covalent immobilization of the specific antibody for TGF- $\beta 1$ using Mix\&Go polymer. A sandwich-type immunoassay was performed using biotin-anti-TGF and conjugation with peroxidase-labeled streptavidin (poly-HRP-Strept) polymer. Amperometric measurements were carried out at $-0.20 \mathrm{~V}$ by adding hydrogen peroxide solution onto the electrode surface in the presence of hydroquinone as the redox mediator. The calibration plot allowed a range of linearity extending between 15 and $3000 \mathrm{pg} / \mathrm{mL}$ TGF- $\beta 1$ which is adequate for the determination of the cytokine in plasma and urine. The limit of detection, $10 \mathrm{pg} / \mathrm{mL}$, is notably improved with respect to those obtained with ELISA kits. The usefulness of the immunosensor for the determination of low TGF- $\beta 1$ concentrations in real samples was evaluated by analyzing spiked urine at different $\mathrm{pg} / \mathrm{mL}$ concentration levels.
\end{abstract}

(c) 2016 Elsevier B.V. All rights reserved.

\section{Introduction}

Cytokines are low molecular weight bioactive proteins produced by many different cells and strongly associated with the immune system (Stenken and Poschenrieder, 2015) (Liu et al., 2016). There is enormous clinical interest in cytokines determination as elevated concentrations of these proteins are associated with inflammation or disease progression and, therefore, various types of cytokines are widely used as biomarkers to characterize the immune function, predict diseases and monitor their evolution and treatments. These applications require the availability of highly sensitive analytical methods because cytokines appear into the extracellular milieu at pM concentration range.

The transforming growth factor- $\beta$ (TGF- $\beta$ ) family is a collection of structurally related multi-functional cytokines which regulates a wide range of physiological and pathological processes. They are involved in cell-growth, rate of proliferation, differentiation and production of extracellular matrix proteins (Grainger et al., 2000). Three isoforms (TGF- $\beta 1,-\beta 2$, and $-\beta 3$ ) are present in mammals with some differences in biological activities and also in their potencies. Particularly, TGF- $\beta 1$ is involved in immune and inflammatory responses showing a hundred times more potent

\footnotetext{
* Corresponding author.

E-mail address: yseo@quim.ucm.es (P. Yáñez-Sedeño).
}

behavior as growth inhibitor of hematopoeitic stem cells than the others. This cytokine has been considered as a good biomarker of liver fibrosis (Fallatah, 2014) or bladder carcinoma (Eder et al., 1996). Increasing evidence also links TGF- $\beta 1$ to the progression of renal fibrosis and scarring associated with diabetic nephropathy or hypertensive nephrosclerosis (Tsapenko et al., 2013) and glomerulonephritis (Grainger et al., 1995). TGF- $\beta 1$ concentration levels between 0.1 and $25 \mathrm{ng} / \mathrm{mL}$ have been reported in plasma from healthy individuals (Grainger et al., 2000). The variability observed depends to some extent on the assay type used for the determination. Circulating levels of TGF- $\beta 1$ increase in patients suffering various types of cancer in addition to the aforementioned kidney diseases, and are severely depressed in advanced atherosclerosis (Matharu et al., 2014).

Despite its importance, relatively few methods are available for the determination of this cytokine. Immunoassay strategies based on sandwich-type configurations with peroxidase-labeled or biotinylated anti-TGF- $\beta 1$ as detection antibodies are employed in commercial ELISA colorimetric kits. These methods are valid for determining TGF- $\beta 1$ in the range from several tens to thousands of $\mathrm{pg} / \mathrm{mL}$ with minimum detectable concentrations that can drop to a few units of $\mathrm{pg} / \mathrm{mL}$. In the particular case of biosensors for TGF- $\beta 1$ determination, only two configurations have been found in the literature. An aptasensor involving aptamer-modified Au electrodes integrated with microfluidics was reported. Thiolated aptamers labeled with methylene blue were self-assembled on gold 
surfaces. The linear range covered up to $250 \mathrm{ng} / \mathrm{mL}$ with a detection limit of $1 \mathrm{ng} / \mathrm{mL}$. This device was used to monitor TGF- $\beta 1$ release from hepatic cells (Matharu, et al., 2014). Very recently, an impedimetric immunosensor was developed for the determination of TGF- $\beta 1$ in human serum. A self-assembled monolayer of polyethylene glycol (PEG) prepared onto interdigitated electrodes was used for the covalent immobilization of the antibodies. A linear impedance vs log [TGF- $\beta 1$ ] range between 1 and 1000 $\mathrm{ng} / \mathrm{mL}$ was found with a detection limit of $0.570 \mathrm{ng} / \mathrm{mL}$ (Yao et al., 2016). However, biosensors exhibiting higher sensitivity are needed to be applied to clinical samples containing very low TGF- $\beta 1$ concentrations. For example, in urine this cytokine ranges typically between 10 and $50 \mathrm{pg} / \mathrm{mL}$ and it has been proposed as a biomarker for patients having or at risk for renal disease (Tsapenko et al., 2013) (Grainger et al., 1995) (Honkanen et al., 1997). Obviously, it is also mostly important the noninvasive nature of collecting urine sample and therefore its usefulness to be employed with point of care devices.

In this work, the first amperometric immunosensor for the quantification of TGF- $\beta 1$ is described, with the objective of developing a sensitive, reliable, and robust analytical tool for the determination of this cytokine in complex clinical samples. The immunosensor implies a disposable device using carboxylic acidfunctionalized magnetic microparticles supported onto screenprinted carbon electrodes. These magnetic beads have demonstrated to be powerful tools for the preparation of electrochemical immunosensors enabling minimization of matrix effects in the analysis of complex samples (Zacco et al., 2006), (Ruiz-Valdepeñas Montiel et al., 2015). Covalent immobilization of the specific antibody for TGF- $\beta 1$ (anti-TGF) was performed using Mix\&Go, a polymer containing several metallic complexes selected for their efficiency to bind proteins (Ojeda et al., 2015). A sandwich-type immunoassay was designed using biotin-anti-TGF, and conjugation with peroxidase-labeled streptavidin (poly-HRP-Strept) polymer was used as to amplify the electrochemical detection. Amperometric measurements were performed by adding hydrogen peroxide solution onto the electrode surface in the presence of hydroquinone as the redox mediator. The analytical usefulness of the immunosensor was demonstrated by application to urine samples containing different TGF- $\beta 1$ concentrations at the $\mathrm{pg} / \mathrm{mL}$ level.

\section{Experimental}

\subsection{Reagents and solutions}

Human TGF- $\beta 1$, mouse capture antibody (anti-TGF), and chicken biotinylated antibody (Biotin-anti-TGF) were from R\&D Systems and included in the DuoSet ${ }^{\mathbb{R}}$ ELISA Development System (DY240-05). Horseradish peroxidase-labeled streptavidin (HRPStrept) (Roche), poly-HRP-Strept (85-R200) (Fitzgerald), carboxylic acid-functionalized magnetic beads (HOOC-MBs) (Dynabeads ${ }^{\text {R8 }} \mathrm{M}-$ 270 Carboxylic Acid, $2.8 \mu \mathrm{m}$ diameter, $30 \mathrm{mg} / \mathrm{mL}$ ), and Mix\&Go ${ }^{\mathrm{TM}}$ polymer from Anteo Diagnostics, were also used. Buffer solutions used were: $0.1 \mathrm{M}$ phosphate buffer solution of $\mathrm{pH} 8.0$ and $0.05 \mathrm{M}$ phosphate buffer solution of $\mathrm{pH} 6.0$ prepared from $\mathrm{Na}_{2} \mathrm{HPO}_{4}$ and $\mathrm{NaH}_{2} \mathrm{PO}_{4}$; saline phosphate buffer of pH 7.2 (PBS) containing $8.1 \mathrm{mM} \mathrm{Na}_{2} \mathrm{HPO}_{4}, 1.5 \mathrm{mM} \mathrm{KH}_{2} \mathrm{PO}_{4}, 137 \mathrm{mM} \mathrm{NaCl}$, and $2.7 \mathrm{mM} \mathrm{KCl}$; washing buffer solution (WBS) prepared from the latter PBS by dissolving $0.05 \%$ Tween 20; 25 mM MES buffer solution of $\mathrm{pH}$ 5.0 prepared from $2-(\mathrm{N}$-morpholine) ethanosulfonic acid (Gerbu). Hydrogen peroxide (Aldrich, 30\% (w/w) and hydroquinone (Sigma) were also used. $2 \mathrm{M}$ ethanolamine (Sigma) prepared in $0.1 \mathrm{M}$ phosphate buffer solution of $\mathrm{pH} 8.0$ was used as blocking solution. Ascorbic acid (AA) (Fluka), uric acid (UA) and creatinine (CR)
(Sigma), adiponectin (APN), interleukin 6 (IL-6) and interleukin 8 (IL-8) (Abcam), and tumor necrosis factor alpha (TNF- $\alpha$ ) (BD Pharmingen) were tested as potential interferents. Deionized water was obtained from a Millipore Milli-Q purification system (18.2 $\mathrm{M} \Omega \mathrm{cm}$ at $25^{\circ} \mathrm{C}$ ).

\subsection{Apparatus and electrodes}

Amperometric measurements were performed using an INBEA potentiostat provided by the IbGraph software. Screen-printed carbon electrodes (SPCEs, 110 DRP, $\phi 4 \mathrm{~mm}$ ) from DropSens (Oviedo, Spain) were used as working electrodes. These electrodes are provided with a silver pseudo-reference electrode and a carbon counter electrode. Incubation steps were performed at $25^{\circ} \mathrm{C}$ using an Optic Ivymen System constant temperature incubator shaker (Comecta S. A.) and $\mathrm{pH}$ measurements were made using a Crison Basic 20+ pHmeter. A P-Selecta ultrasonic bath, a magnetic separator (DynaMagn ${ }^{\mathbb{R}}$, Invitrogen Dynal), and a Vortex homogenizator from Heidolph were also used. All experiments were performed at room temperature.

\subsection{Procedures}

\subsubsection{Preparation of the poly-HRP-Strept/Biotin-anti-TGF/TGF- $\beta 1 /$ anti-TGF-MBs-conjugates}

$3 \mu \mathrm{L}$ of the commercial HOOC-MBs suspension were transferred into a $1.5 \mathrm{~mL}$ Eppendorf tube and washed twice with $50 \mu \mathrm{L}$ of MES buffer solution at $25{ }^{\circ} \mathrm{C}$. Each washing step consisted of a re-suspension of the functionalized MBs in the buffer solution and stirring at $600 \mathrm{rpm}$ for $10 \mathrm{~min}$ (up to homogenization) followed by magnetic separation for $4 \mathrm{~min}$ and removal of the solution. Next, $25 \mu \mathrm{L}$ of Mix\&Go were added and incubated for $60 \mathrm{~min}$ at $25^{\circ} \mathrm{C}$ under stirring at $600 \mathrm{rpm}$. Thereafter, two washing steps with WBS were carried out and, further, $25 \mu \mathrm{L}$ of a $5 \mu \mathrm{g} / \mathrm{mL}$ anti-TGF solution prepared in $25 \mathrm{mM}$ MES buffer solution of $\mathrm{pH} 5.0$ were added, allowing incubation for $60 \mathrm{~min}$ at $25^{\circ} \mathrm{C}$ under stirring at $600 \mathrm{rpm}$. Then, the immunoconjugates were washed firstly with $50 \mu \mathrm{L}$ of $25 \mathrm{mM}$ MES buffer solution of pH 5.0 and, secondly, with $50 \mu \mathrm{L}$ of $100 \mathrm{mM}$ PBS of $\mathrm{pH}$ 8.0. Next, a blocking step by incubation of the anti-TGF-MBs conjugate with $50 \mu \mathrm{L}$ of $2 \mathrm{M}$ ethanolamine solution prepared in $0.1 \mathrm{M}$ PBS of $\mathrm{pH} 8.0$ was applied for $1 \mathrm{~h}$. Thereafter, the excess of ethanolamine was removed by washing successively with $50 \mu \mathrm{L}$ of the same PBS buffer and with $50 \mu \mathrm{L}$ of the WBS. Bioconjugation of the target cytokine was carried out by adding $25 \mu \mathrm{L}$ of a TGF- $\beta 1$ standard solution or the sample and incubating for $60 \mathrm{~min}$ at $25^{\circ} \mathrm{C}$. Two washings with $50 \mu \mathrm{L}$ WBS were performed and $25 \mu \mathrm{L}$ of a $2 \mu \mathrm{g} / \mathrm{mL}$ Biotin-anti-TGF- $\beta 1$ solution containing $1 \%$ BSA were added and incubated for 60 min at $25{ }^{\circ} \mathrm{C}$ under stirring at $600 \mathrm{rpm}$. Then, two washing steps with $50 \mu \mathrm{L}$ WBS were applied followed by the addition of $25 \mu \mathrm{L}$ of $1 /$ 500 diluted poly-HRP-Strept in PBS, and incubation for $20 \mathrm{~min}$. Finally, two more washing steps with $50 \mu \mathrm{L}$ WBS were applied. All buffer solutions used were those recommended by the supplier of DuoSet $^{\mathbb{R}}$ ELISA Development System (DY240-05).

\subsubsection{Determination of TGF- $\beta 1$}

The as prepared poly-HRP-Strept/Biotin-anti-TGF/TGF- $\beta 1 /$ antiTGF-MBs were re-suspended in $45 \mu \mathrm{L}$ of $1 \mathrm{mM}$ hydroquinone and transferred onto the surface of the SPCE. This was done by keeping the SPCE horizontal and placing a neodymium magnet on the bottom part of the electrode to locate in a reproducible way the biofunctionalized MBs onto the working electrode surface area. A detection potential of $-200 \mathrm{mV}$ was applied and the background current was recorded until stabilization (100 s approximately). Further, a $5 \mu \mathrm{L}$ aliquot of $50 \mathrm{mM}$ hydrogen peroxide solution was added and, after a period of $200 \mathrm{~s}$ for the enzymatic reaction to 
take place, the reduction current of the formed quinone was measured.

\subsubsection{Analysis of spiked urine}

The procedure described above was applied to urine samples which were spiked with TGF- $\beta 1$ at final concentrations of 25,45 or $100 \mathrm{pg} / \mathrm{mL}$. No pretreatment was required except a $1: 3$ dilution with $0.1 \mathrm{M}$ PBS of $\mathrm{pH}$ 7.2. The determination of TGF- $\beta 1$ was carried out by interpolation of the amperometric responses for the samples into the calibration plot constructed with TGF- $\beta 1$ standards.

\section{Results and discussion}

Fig. 1 shows schematically the different steps involved in the preparation and functioning of the poly-HRP-Strept/Biotin-antiTGF/TGF- $\beta 1 /$ anti-TGF-MBs/SPCE immunosensor. Covalent immobilization of capture antibodies onto carboxylic acid-functionalized magnetic microparticles (step 1) was carried out by using the polymer Mix\&Go. This polymer uses ligands to bind Fc domains that mimic those binding domains from proteins $A$ and $G$ (Ooi et al., 2014), and can also interact strongly with electron donating moieties such as dissociated carboxyl groups. Therefore, combination of HOOC-MBs with the use of Mix\&Go for antibody immobilization resulted in a convenient methodology to be applied as a general route for the preparation of electrochemical immunosensors (Ojeda et al., 2015). Capture antibodies immobilization was followed by a blocking step with ethanolamine (step 2) and the implementation of a sandwich-type immunoassay employing a biotinylated secondary antibody and poly-HRP-Strept for signal amplification (step 3). The use of poly-HRP-Strept instead of conventional HRP-Strept conjugate has demonstrated to be advantageous for the design of sensitive electrochemical immunosensors as multiple HRP molecules are available to biocatalyze $\mathrm{H}_{2} \mathrm{O}_{2}$ reduction (Ojeda et al., 2014). Once the MBs bearing the immuno-conjugates were transferred to the surface of SPCE, hydrogen peroxide was added (step 4) and the amperometric response at $-200 \mathrm{mV}$ in the presence of hydroquinone was measured according to the reactions displayed in Fig. 1.

\subsection{Optimization of the experimental variables involved in the pre- paration of the immunosensor}

The effect of the different variables involved in the preparation of the TGF- $\beta 1$ immunosensor on the corresponding analytical responses was studied. The amount of Mix\&Go used was that optimized previously in our group (Ojeda et al., 2015) and, in these studies, conventional HRP-Strep was used to label the detection antibody since the effect of the other variables should not depend on the type of label employed.

The anti-TGF loading on the carboxylic acid-functionalized MBs was optimized by measuring the specific and unspecific responses (without sandwiched antigen) with antibody concentrations ranging between 2.5 and $20 \mu \mathrm{g} / \mathrm{mL}$. Fig. 2(a) shows as the largest specific-to-unspecific current ratio was obtained for a $5 \mu \mathrm{g} / \mathrm{mL}$ antibody concentration. Higher concentrations produced a significant decrease of the specific response most likely due to hindering of the electrochemical reaction in the presence of a large biomolecule loading. Accordingly, such a concentration was selected to construct the immunosensor. Optimization of the incubation time for this step (results not shown) led us to select 60 min for the covalent binding of the antibody.

Ethanolamine was chosen as the blocking agent to minimize unspecific adsorptions onto HOOC-MBs after anti-TGF binding due to its proved efficiency for this purpose (Ojeda et al., 2014). In order to optimize this blocking step, 1 and $2 \mathrm{M}$ ethanolamine solutions and different incubation times over 30-90 min range were tested. Fig. 2(b) and (c) show as an effective blocking was reached using a $2 \mathrm{M}$ ethanolamine solution for $60 \mathrm{~min}$. Under these conditions, the current due to unspecific adsorption was less than $25 \%$ than that measured for such a low TGF- $\beta 1$ concentration as $125 \mathrm{pg} / \mathrm{mL}$.

The Biotin-anti-TGF concentration was also optimized by testing the electrochemical responses measured with different
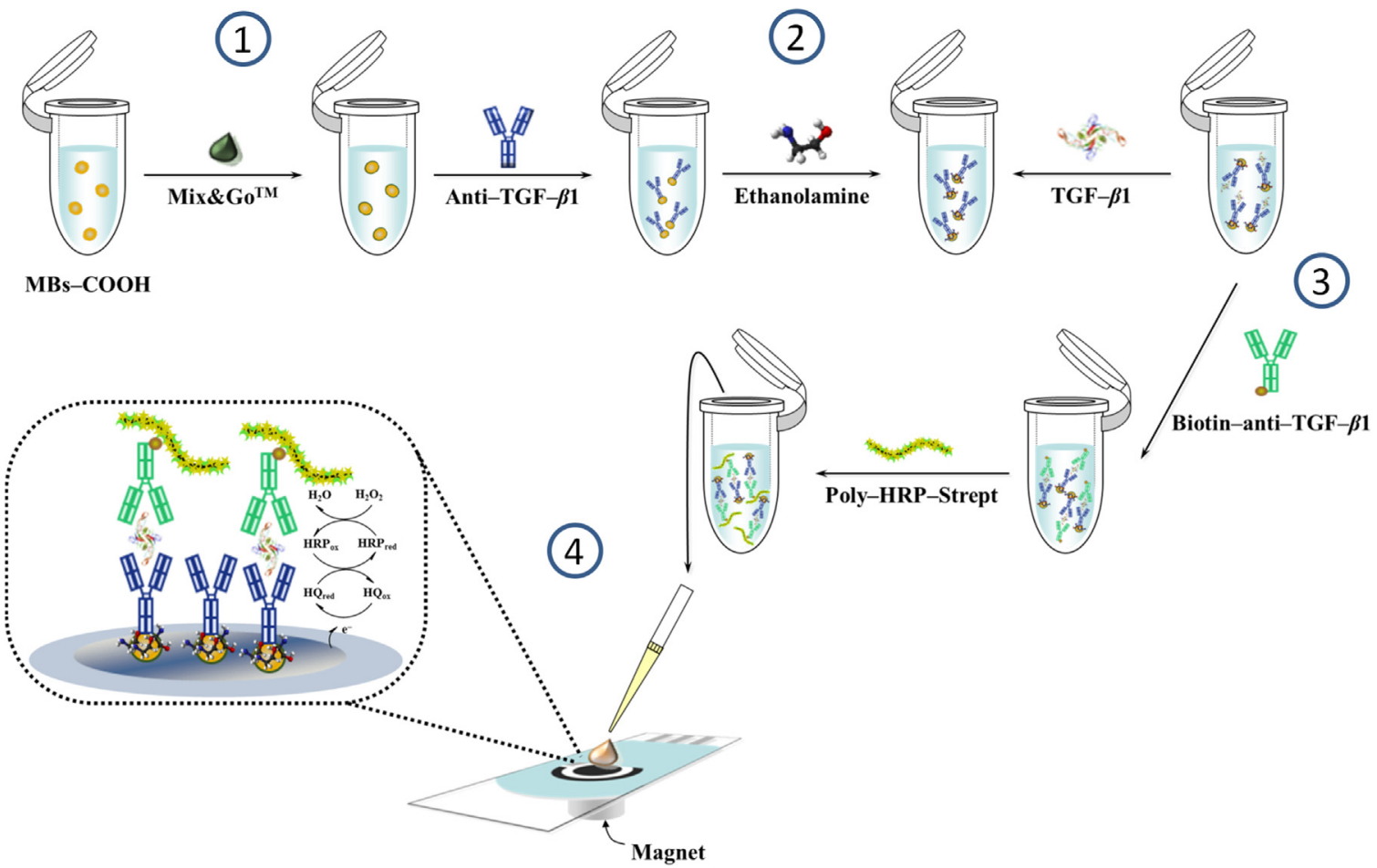

Fig. 1. Schematic display of the different steps involved in the preparation of the amperometric immunosensor for TGF- $\beta 1$. 
a

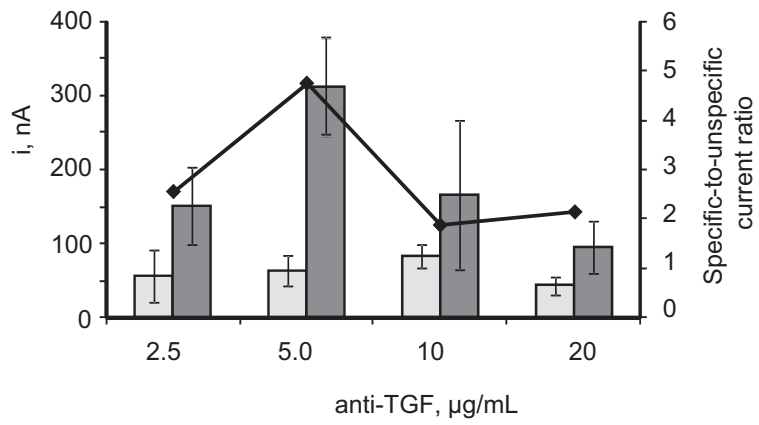

C

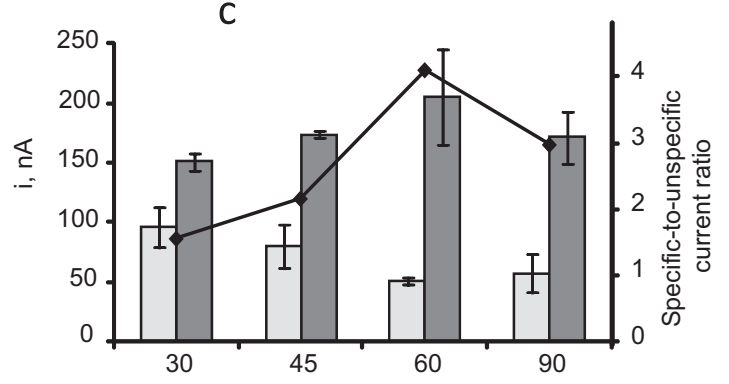

Blocking step, min b

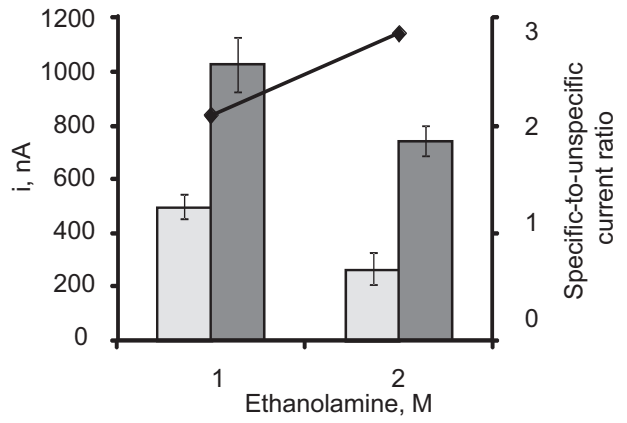

d

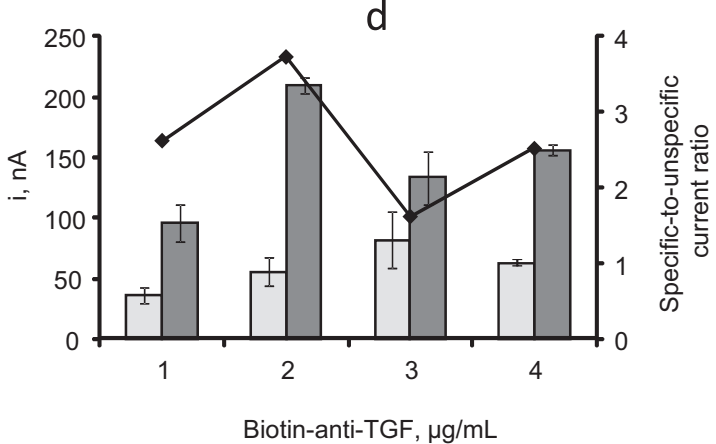

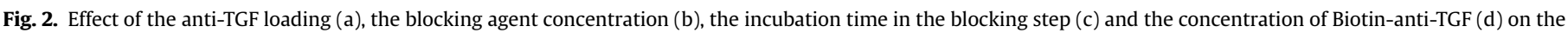

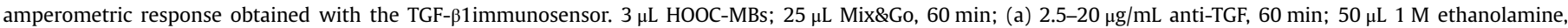

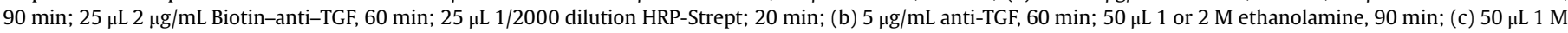

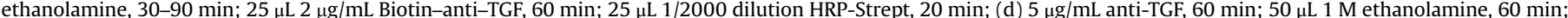

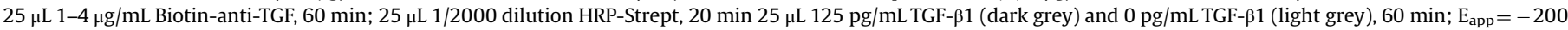
$\mathrm{mV}$. See the text for more information. Triplicate measurements with error bars at $\pm \mathrm{s}$ values.

immunosensors prepared with conjugate loadings over the 1-4 $\mu \mathrm{g} / \mathrm{mL}$ range. Results obtained (Fig. 2(d)) showed an increase in the amperometric response with increasing the Biotin-anti-TGF concentration between 1 and $2 \mu \mathrm{g} / \mathrm{mL}$. Larger concentrations produced smaller and rather similar responses suggesting saturation of the antibodies binding sites. Accordingly, $2 \mu \mathrm{g} / \mathrm{mL}$ was a

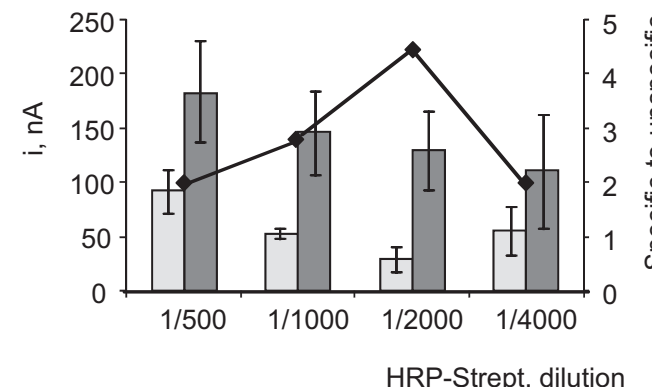

b

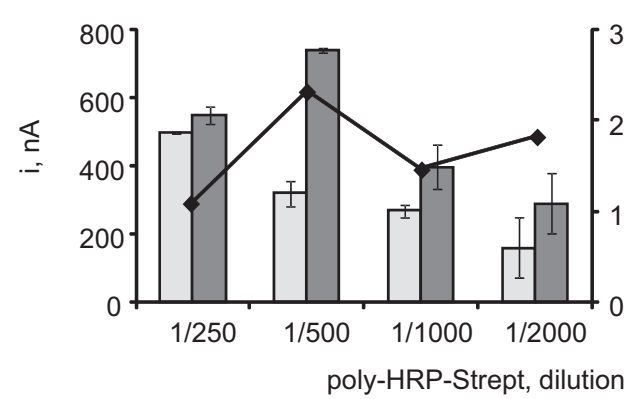

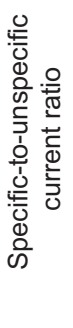

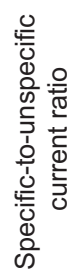

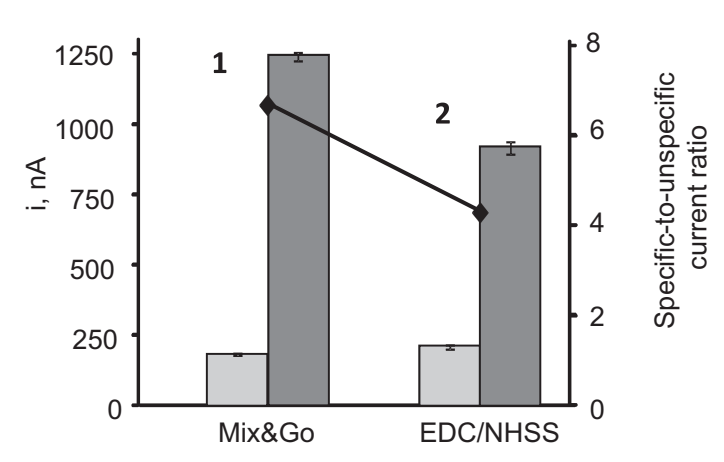

C

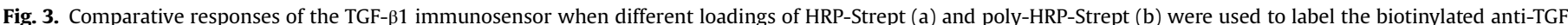

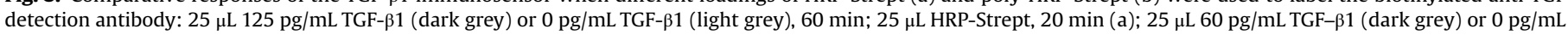

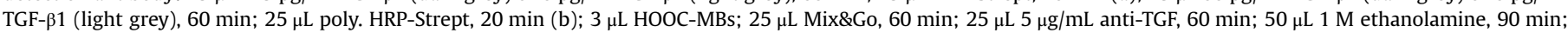

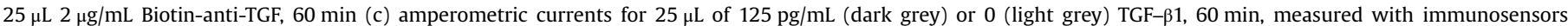

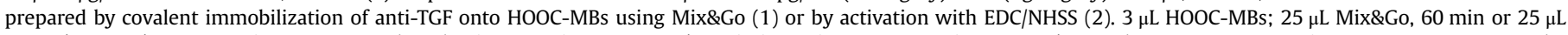

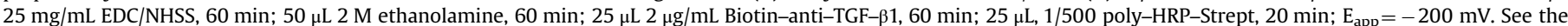
text for more information. Results for triplicate analysis with error bars at $\pm s$ values. 
chosen as the optimal conjugate concentration. Regarding the incubation time for this step (results not shown), a period of $60 \mathrm{~min}$ was shown be enough to allow binding of all biotinylated antibodies to TGF- $\beta 1$ antigen.

In order to get the highest possible sensitivity to achieve the goal mentioned in the Introduction for this work, an electrochemical signal amplification strategy was implemented by labeling the detection antibody with a peroxidase-streptavidin polymer instead of conventional HRP-Strept. This strategy has demonstrated to enhance sensitivity in the preparation of electrochemical immunosensors since multiple HRP molecules are available to be used in the biocatalysis of the enzyme substrate (Ojeda et al., 2014). The foreseen amplification effect provoked by the use of poly-HRP-Strept was confirmed by comparing the responses obtained with both conjugates. Fig. 3(a) shows the results when HRP-Strept was employed with dilution factors ranging from $1 / 500$ to $1 / 4000$. The specific response for a TGF- $\beta 1$ concentration of $125 \mathrm{pg} / \mathrm{mL}$ slightly decreased when the conjugate concentration was lower while the best specificto-unspecific current ratio was obtained for a 1/2000 HRP-Strept dilution. When poly-HRP-Strept was employed, a remarkable larger current was measured (Fig. 3(b)) for a TGF- $\beta 1$ concentration of $60 \mathrm{pg} / \mathrm{mL}$, thus demonstrating the achieved amplification in the electrochemical response. In this case, the largest specific-to-unspecific current ratio occurred for a 1/500 dilution factor and, as it could be expected, it was significantly smaller than that occurring with HRP-Strept. In both cases, an incubation time of 20 min was enough for binding with the biotinylated secondary antibody.

As commented above, the strategy for binding capture antibodies to carboxylic acid-functionalized MBs implied the use of the Mix\&Go polymer. This was claimed as an efficient strategy for the stable and oriented binding of antibodies (Ojeda et al., 2015) and, in this case, it was demonstrated by comparing the immunosensor response when anti-TGF antibodies were covalently immobilized using Mix\&Go, with that obtained when conventional EDC/NHSS chemistry was employed for the antibody binding. As Fig. 3(c) shows, a remarkably enhanced specific-to-background current was apparent when anti-TGF was immobilized using Mix\&Go, probably as a consequence of the suitable orientation of the antibody provided by this polymer.

\subsection{Analytical characteristics of the immunosensor}

Fig. 4 shows the calibration plot for TGF- $\beta 1$ constructed with the developed immunosensor under the optimized working conditions. Error bars were calculated from measurements carried out with three different immunosensors in each case. The steady state current vs. logarithm of TGF- $\beta 1$ concentration followed the adjusted equation $\mathrm{I}(\mathrm{nA})=978 \log \mathrm{C}(\mathrm{pg} / \mathrm{mL})-734\left(\mathrm{r}^{2}=0.991\right)$, with a range of linearity extending between 15 and $3000 \mathrm{pg} / \mathrm{mL}$ TGF- $\beta 1$. This range covers more than two orders of magnitude and it is adequate for the determination of the cytokine in real samples taking into account the expected concentrations, at $\mathrm{ng} / \mathrm{mL}$ level in plasma (Grainger et al., 1995), or tens of $\mathrm{pg} / \mathrm{mL}$ in urine (Tsapenko et al., 2013). The limit of detection, $10 \mathrm{pg} / \mathrm{mL}$, was calculated by applying the $3 s_{b}$ criterion, where $s_{b}$ was estimated as the standard deviation in concentration units $(n=10)$ of measured blank currents $(0 \mathrm{ng} / \mathrm{mL}$ TGF- $\beta 1)$. The analytical characteristics achieved with the proposed immunosensor improve notably those reported for the commercial ELISA kits. For example, RayBio ${ }^{\mathbb{B}}$ Human TGFbeta1 ELISA kit (ELH-TGFb1) claims (〈www.raybiotech.com/files/ manual/ELISA/ELH-TGFb1.pdf $\rangle$ ) for a minimun detectable dose (analyte concentration resulting in an absorbance equal to $2 \mathrm{~s}$ higher than that of the blank) of $80 \mathrm{pg} / \mathrm{mL}$, which is eight times higher than that achieved in this work. The immunosensor exhibits also remarkably higher sensitivity than that reported for both the aptasensor (LOD of $1 \mathrm{ng} / \mathrm{mL}$ ) (Honkanen et al., 1997) and the impedimetric imunosensor ( $\mathrm{LOD}=0.570 \mathrm{ng} / \mathrm{mL}$ ) (Yao et al., 2016).

The reproducibility of the amperometric responses obtained with different immunosensors was evaluated. Sets of immunosensors were prepared on the same day and on different days using a new anti-TGF-MBs/SPCE in each case. The relative standard deviation (RSD) $(n=5)$ values were $2.9 \%$ and $3.9 \%$ for the assays performed on the same day in the absence and in the presence of $250 \mathrm{pg} / \mathrm{mL}$ TGF- $\beta 1$, respectively, whereas RSD $(n=5)$ values were $3.7 \%$ and $4.2 \%$, respectively, for the measurements made on different days. These results revealed the good level of precision achieved in the fabrication and functioning of the proposed immunosensing platform. Moreover, the storage ability of anti-TGF-MBs/SPCE conjugates was also tested. Different anti-TGF-MBs/SPCE were prepared on the same day, stored under humidity conditions at $4{ }^{\circ} \mathrm{C}$, and employed to prepare immunosensors to measure $250 \mathrm{pg} / \mathrm{mL}$ TGF$\beta 1$ on different days. The results obtained (not shown) indicated that the immunosensor responses remained within the control limits, located at $\pm 3 \mathrm{~s}$, were $\mathrm{s}$ was the standard deviation of the measurements $(\mathrm{n}=10)$ carried out on the first working day, for at least 30 days (no longer storage times were tested) demonstrating the good stability of the anti-TGF-MBs/SPCE conjugates.
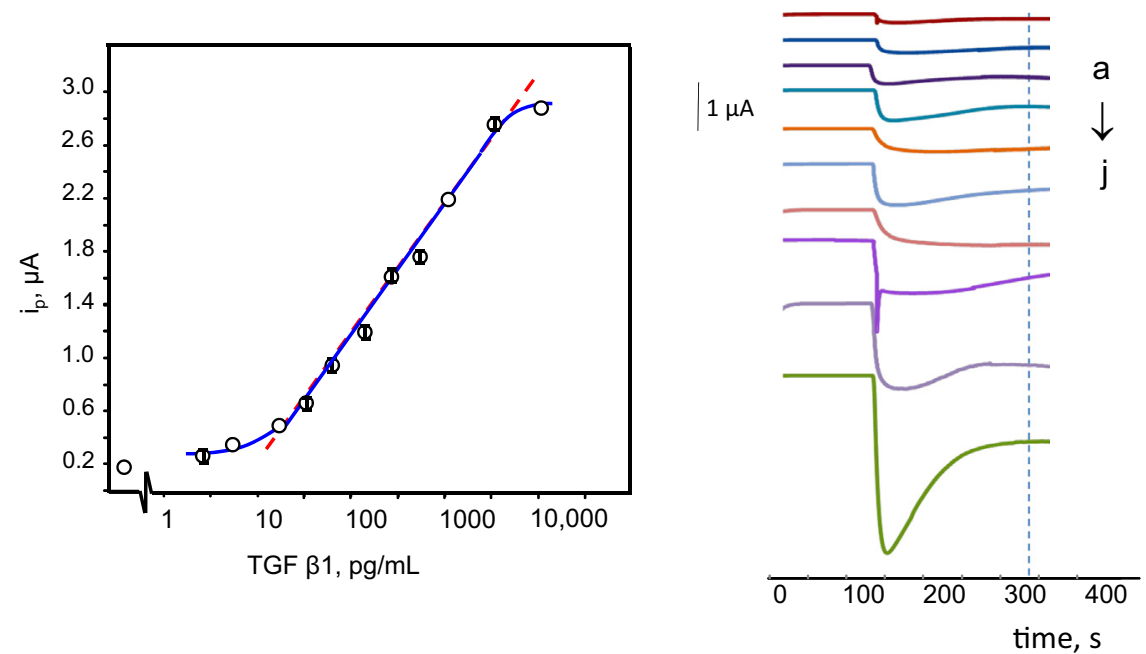

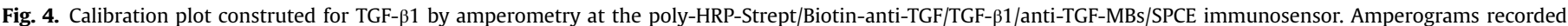
for a) 0 ; b) 2.5 ; c) 15 ; d) 30 ; e) 60 ; f) 125 ; g) 250 ; h) 500 ; i) 1000 ; j) 3000 pg/mL TGF- $\beta 1$. Dotted line indicates the time of measurement. 


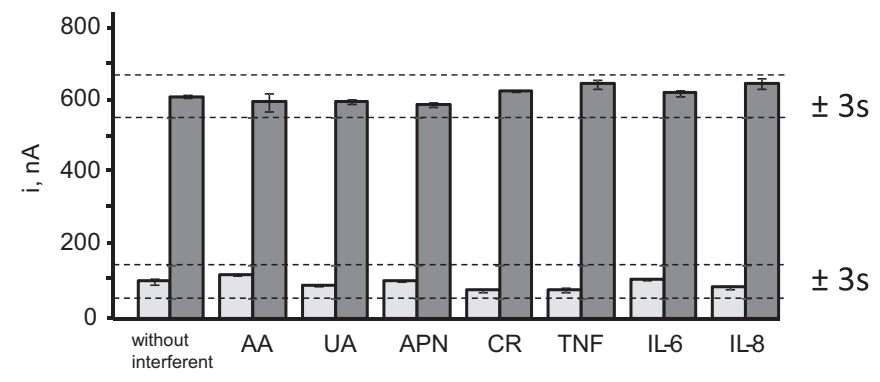

Fig. 5. Amperometric responses measured with the poly-HRP-Strept/Biotin-antiTGF/TGF- 1 1/anti-TGF-MBs/SPCE immunosensor for 0 (light grey) and $25 \mathrm{pg} / \mathrm{mL}$ TGF- $\beta 1$ (dark grey) in the presence of $370 \mu \mathrm{g} / \mathrm{mL}$ ascorbic acid (AA), $50 \mu \mathrm{g} / \mathrm{mL}$ uric acid (AU), $200 \mathrm{pg} / \mathrm{mL}$ adiponectin (APN), $10 \mathrm{pg} / \mathrm{mL}$ creatinine (CR), $200 \mathrm{pg} / \mathrm{mL}$ tumor necrosis factor alpha (TNF), $500 \mathrm{pg} / \mathrm{mL}$ interleukin 6 (IL-6), and $10 \mathrm{ng} / \mathrm{mL}$ interleukin 8 (IL-8).

Table 1

Determination of TGF- $\beta 1$ in spiked urine with the poly-HRP-Strept/Biotin-anti-TGF/ TGF- $\beta 1 /$ anti-TGF-MBs/SPCE immunosensor.

\begin{tabular}{ccc}
\hline TGF- $\boldsymbol{\beta} 1, \mathbf{p g} / \mathbf{m L}$ & TGF- $\beta 1$ found, pg/mL & Recovery, \% \\
\hline 25 & $25.9 \pm 0.5$ & $103 \pm 8$ \\
45 & $44.9 \pm 0.3$ & $100 \pm 3$ \\
100 & $96 \pm 1$ & $97 \pm 5$ \\
\hline
\end{tabular}

The used antibody also exhibited a great selectivity against other proteins. Fig. 5 displays the immunosensor responses in the absence and in the presence of $25 \mathrm{pg} / \mathrm{mL}$ TGF- $\beta 1$, and in the presence of ascorbic acid (AA), uric acid (UA), adiponectin (APN), creatinine (CR), tumor necrosis factor alpha (TNF), interleukin 6 (IL-6) or interleukin 8 (IL-8) at the expected concentrations in healthy patients. As it is clearly seen, no significant differences were apparent in any case. Interestingly, due to the detection potential value used, no interference from electroactive substances such as ascorbic and uric acids was observed.

\subsection{Determination of TGF- $\beta 1$ in spiked urine}

The usefulness of the immunosensor for the determination of low TGF- $\beta 1$ concentrations in real samples was evaluated by analyzing spiked urine following the procedure described in section 2.3.3. The sample used was Liquichek ${ }^{\mathrm{TM}}$ Urine Chemistry Control (BioRad) containing uric acid, amilase, calcium, chloride, cortisol, creatinine, phosphorous, glucose, magnesium, albumin, potassium, sodium, and urea, and it was spiked with TGF- $\beta 1$ at 25 , 45 or $100 \mathrm{pg} / \mathrm{mL}$ concentration levels.

The possibility of a matrix effect was evaluated by constructing calibration graphs in urine by spiking it with TGF- $\beta 1$ concentrations ranging between 25 and $250 \mathrm{pg} / \mathrm{mL}$ and applying $0,1: 2$ and $1: 3$ dilution ratios with $0.1 \mathrm{M}$ PBS of $\mathrm{pH}$ 7.2. The results obtained revealed that a $1: 3$ dilution was enough to avoid significant matrix effects since the slope of the calibration plot, $911 \mathrm{nA}$ per decade of concentration, was not statistically different from that obtained with TGF- $\beta 1$ standards. Accordingly, the determination of TGF- $\beta 1$ in urine could be accomplished by interpolation of the current measured with the immunosensor in the 1:3 diluted samples into calibration plot prepared with standards. No other sample pretreatment was needed in any case. Table 1 summarizes the results obtained in the analysis of spiked urine with recoveries near to $100 \%$ in all cases, thus demonstrating the suitability of the approach to determine low TGF- $\beta 1$ concentrations in a complex biological fluid such urine is.

\section{Conclusions}

The first amperometric immunosensor for the quantification of the cytokine TGF- $\beta 1$, proposed as a biomarker for patients having or at risk for renal disease, is described in this work. The rational design of the immunosensor involving stable and oriented immobilization of the specific antibodies on carboxylic acid-functionalized MBs by using the polymer Mix\&Go, and an electrochemical signal amplification strategy by labeling the detection antibody with a peroxidase-streptavidin polymer, allowed remarkably improved analytical characteristics to be obtained with respect to ELISA kits or previous methods. Combining these benefits, a calibration plot suitable for the determination of the cytokine in plasma and urine is achieved. This allowed the determination of TGF- $\beta 1$ concentrations in urine at the $\mathrm{pg} / \mathrm{mL}$ concentration level with no sample treatment except a 1:3 dilution with buffer solution. The obtained results show that the initial objective of developing a sensitive, reliable, and robust analytical tool for the determination of this cytokine in complex clinical samples, and, therefore, suitable to develop point-of-care devices is reasonably achieved.

\section{Acknowledgments}

Financial support of Spanish Ministerio de Economía y Competitividad, Research Project CTQ2015-70023-R, and NANOAVANSENS Program from Comunidad de Madrid (S2013/MT-3029) is gratefully acknowledged.

\section{References}

Eder, I.E., Stenzl, A., Hobisch, A., Cronauer, M.V., Bartsch, G., Klocker, H., 1996. J. Urol. 156, 953-957.

Fallatah, H.I., 2014. Advances in. Hepatology, 357287.

Grainger, D.J., Kemp, B.R., Metcalfe, J.C., Liu, A.C., Lawn, R.M., Williams, N.R., Grace, A.A., Schofield, P.M., Chauhan, A., 1995. Nat. Med. 1, 74-79.

Grainger, D.J., Mosedale, D.E., Metcalfe, J.C., 2000. Cytokine Growth Factor Rev. 11, 133-145.

Honkanen, E., Teppo, A.-M., Törnroth, T., Groop, P.-H., Grönhagen-Riska, G., 1997. Nephrol. Dial. Transpl. 12, 2562-2568.

Liu, G., Qi, M., Hutchinson, M.R., Yang, G., Goldys, E.M., 2016. Biosens. Bioelectron. 79, 810-815.

Matharu, Z., Patel, D., Gao, Y., Haque, A., Zhou, Q., Revzin, A., 2014. Anal. Chem. 86, 8865-8872.

Ojeda, I., Moreno-Guzmán, M., González-Cortés, A., Yáñez-Sedeño, P., Pingarrón, J M., 2014. Anal. Bioanal. Chem. 406, 6363-6371.

Ojeda, I., Barrejón, M., Arellano, L.M., González-Cortés, A., Yáñez-Sedeño, P., Langa, F. Pingarrón, J.M., 2015. Biosens. Bioelectron. 74, 24-29.

Ooi, H.W., Cooper, S.J., Huang, C.-Y., Jennins, D., Chung, E., Maeji, N.J., Whittaker, A. K., 2014. Anal. Biochem. 456, 6-13.

Ruiz-Valdepeñas Montiel, V., Campuzano, S., Pellicanò, A., Torrente-Rodríguez, R.M., Reviejo, A.J., Cosio, M.S., Pingarrón, J.M., 2015. Anal. Chim. Acta 880, 52-59.

Stenken, J.A., Poschenrieder, A.J., 2015. Anal. Chim. Acta 853, 95-99.

Tsapenko, M.V., Nwoko, R.E., Borland, T.M., Voskoboev, N.V., Pflueger, A., Rule, A.D. Lieske, J.C., 2013. Clin. Biochem. 46, 1430-1435.

Yao, Y., Bao, J., Lu, Y., Zhang, D., Luo, S., Cheng, X., Zhang, Q., Li, S., Liu, Q., 2016. Sens. Actuators, B 222, 127-132.

Zacco, E., Pividori, M.I., Alegret, S., Galve, R., Marco, M.P., 2006. Anal. Chem. 78, 1780-1788.

〈www.raybiotech.com/files/manual/ELISA/ELH-TGFb1.pdf . 